\title{
Recipient female gender is a risk factor for graft loss after liver transplantation for chronic hepatitis C: Evidence from the prospective Liver Match cohort
}

\author{
Luca Saverio Belli ${ }^{\mathrm{a}, *}$, Renato Romagnoli ${ }^{\mathrm{b}}$, Alessandra Nardi ${ }^{\mathrm{c}}$, Tania Marianelli ${ }^{\mathrm{c}}$, \\ Francesca Donato $^{\mathrm{d}}$, Stefano Ginanni Corradini ${ }^{\mathrm{e}}$, Rosa Maria Iemmolo ${ }^{\mathrm{f}}$, Cristina Morelli ${ }^{\mathrm{g}}$, \\ Luisa Pasulo $^{\mathrm{h}}$, Maria Rendina ${ }^{\mathrm{i}}$, Eleonora De Martin ${ }^{\mathrm{j}}$, Francesca Romana Ponziani ${ }^{\mathrm{k}}$, \\ Riccardo Volpes ${ }^{1}$, Mario Strazzabosco ${ }^{\mathrm{m}}$, Mario Angelico ${ }^{\mathrm{n}}$, Liver Match Investigators \\ a Department of Hepatology and Gastroenterology, Niguarda Hospital, Milan, Italy \\ b Liver Transplant Center, Azienda Ospedaliera Città della Salute e della Scienza, University of Turin, Italy \\ ' Department of Mathematics, Tor Vergata University Hospital, Rome, Italy \\ d Division of Digestive Diseases, “Maggiore” University Hospital, Milan, Italy \\ e Division of Gastroenterology, Sapienza University, Rome, Italy \\ ${ }^{\mathrm{f}}$ Liver Transplant Center, University Hospital, Modena, Italy

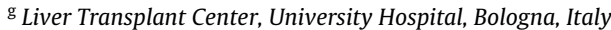 \\ Gastroenterology and Transplant Hepatology, San Giovanni XXIII Hospital, Bergamo, Italy \\ i Department of Emergency and Organ Transplantation, University Hospital, Bari, Italy \\ j Liver Transplant Center, University Hospital, Padua, Italy \\ ${ }^{\mathrm{k}}$ Department of Internal Medicine and Gastroenterology, Gemelli Hospital, Rome, Italy \\ ${ }^{1}$ Mediterranean Institute for Transplant, Palermo, Italy \\ m Digestive Disease Section, University Hospital Milano Bicocca and Yale University Center, New Haven, USA \\ ${ }^{\mathrm{n}}$ Hepatology Unit, Tor Vergata University, Rome, Italy
}

\section{A R T I C L E I N F O}

\section{Article history:}

Received 26 February 2015

Accepted 8 April 2015

Available online 16 April 2015

Keywords:

Donor age

Graft loss

$\mathrm{HCV}$

HCV recurrence

Liver transplantation

Recipient gender

\begin{abstract}
A B S T R A C T
Background: Female gender has been reported to be a risk factor for graft loss after liver transplantation for hepatitis C virus (HCV)-related cirrhosis but evidence is limited to retrospective studies.

Aims: To investigate the impact of recipient gender and donor/recipient gender mismatch on graft outcome.

Methods: We performed a survival analysis of a cohort of 1530 first adult transplants enrolled consecutively in Italy between 2007 and 2009 and followed prospectively. After excluding possible confounding factors (fulminant hepatitis, human immunodeficiency virus co-infection, non-viremic anti-HCV positive subjects), a total of 1394 transplant recipients (604 HCV-positive and $790 \mathrm{HCV}$-negative) were included. Results: Five-year graft survival was significantly reduced in $\mathrm{HCV}$-positive patients (64\% vs $76 \%$, $p=0.0002)$; Cox analysis identified recipient female gender ( $\mathrm{HR}=1.44,95 \% \mathrm{CI} 1.03-2.00, p=0.0319)$, Mayo clinic End stage Liver Disease score (every 10 units, $\mathrm{HR}=1.25,95 \% \mathrm{CI} 1.03-1.50 ; p=0.022$ ), portal thrombosis $(\mathrm{HR}=2.40,95 \% \mathrm{CI} 1.20-4.79, p=0.0134)$ and donor age (every 10 years, $\mathrm{HR}=1.14,95 \% \mathrm{CI} 1.05-1.24$, $p=0.0024$ ) as independent determinants of graft loss. All additional mortality observed among female recipients was attributable to severe HCV recurrence. Conclusions. This study unequivocally shows that recipient female gender unfavourably affects the outcome of HCV-infected liver grafts.
\end{abstract}

(c) 2015 Editrice Gastroenterologica Italiana S.r.l. Published by Elsevier Ltd. All rights reserved.
* Corresponding author at: Department of Hepatology and Gastroenterology, Niguarda Hospital, Piazza Ospedale Maggiore 3, 20162 Milan. Italy. Tel.: +39026444 4436; fax: +390264442788.

E-mail address: luca.belli@ospedaleniguarda.it (L.S. Belli).

\section{Introduction}

Donor and recipient factors influence the outcome of liver transplantation (LT) in individuals infected with hepatitis C virus (HCV). Some of the risk factors, such as donor age and Model for End-stage Liver Disease (MELD) score, are well-established [1]. The role of gender as a risk factor for graft loss after LT remains unclear, and 
evidence is limited to retrospective studies, suggesting that, in anti$\mathrm{HCV}$-positive recipients, the risk for graft loss is increased in female recipients.

Natural history studies of HCV infection show that chronic liver disease progresses at unequal rates between women and men, as women experience a slower rate of fibrosis progression per year [2] and a lower incidence of end-stage liver disease compared to men [3]. Quite surprisingly, recipient gender seems to play an opposite role in the transplant setting, with at least two retrospective studies reporting that female gender is a risk factor for a rapidly progressive HCV recurrence after LT [4,5]. A large retrospective study [6] showed that anti-HCV-positive female recipients have an increased risk of graft failure only when they receive a graft from a male donor. This finding has not been confirmed in other retrospective studies, and it has not been tested prospectively and against other relevant covariates.

The Liver Match is a prospective observational cohort including 1530 consecutive first transplants performed in adult recipients in Italy between June 2007 and May 2009 for which detailed baseline and follow-up information regarding both donors and recipients have been prospectively recorded [7]. This Italian cohort is therefore optimally suited for a prospective assessment of the role of gender, donor/recipient gender mismatch and other donor/recipient covariates on graft outcome, particularly in the subgroup of recipients in whom the liver graft undergoes HCV reinfection because of detectable HCV-RNA in serum at the time of LT [8].

\section{Patients and methods}

\subsection{Patient population and recorded variables}

Twenty transplant centres, representing approximately $90 \%$ of the whole adult liver transplantation activity performed in Italy, agreed to participate to the data collection through the recruitment of 1530 adult first transplants from deceased heart-beating donors performed between June 1, 2007 and May 31, 2009. Baseline data regarding donor and recipient, the various steps of organ procurement/allocation and follow-up data were recorded prospectively, as already described in detail [7].

\subsubsection{Donor data}

The donor data relevant to this study were age, gender, cause of death, cold ischaemia time (CIT), body mass index (BMI), height, history of diabetes mellitus, positivity for anti-hepatitis B core antigen antibodies (anti-HBc), donor risk index (DRI) [9], serum sodium and split liver.

\subsubsection{Recipient data at liver transplantation}

The following recipient data were recorded at the time of LT: age, gender, donor/recipient sex mismatch, aetiology of liver disease, BMI, presence of hepatocellular carcinoma (HCC) within or outside the Milan criteria, MELD score, sodium, INR, creatinine, bilirubin, previous upper abdominal surgery, presence of complete portal vein thrombosis, insulin dependent diabetes mellitus (IDDM), positivity for anti-HCV antibodies, serum HCV-RNA positivity and HCV genotype. For serum HCV-RNA detection, real time PCR techniques were available in all centres with lower detection limits ranging between 8 and $25 \mathrm{IU} / \mathrm{mL}$.

\subsubsection{Post-liver transplant characteristics}

The following variables were also recorded after LT: maintenance main immunosuppressant (cyclosporine A, tacrolimus, or other drug), acute rejection episodes requiring additional treatment, serum HCV-RNA positivity within the first 6 months after LT, antiviral treatment with peg-interferon alpha and ribavirin,

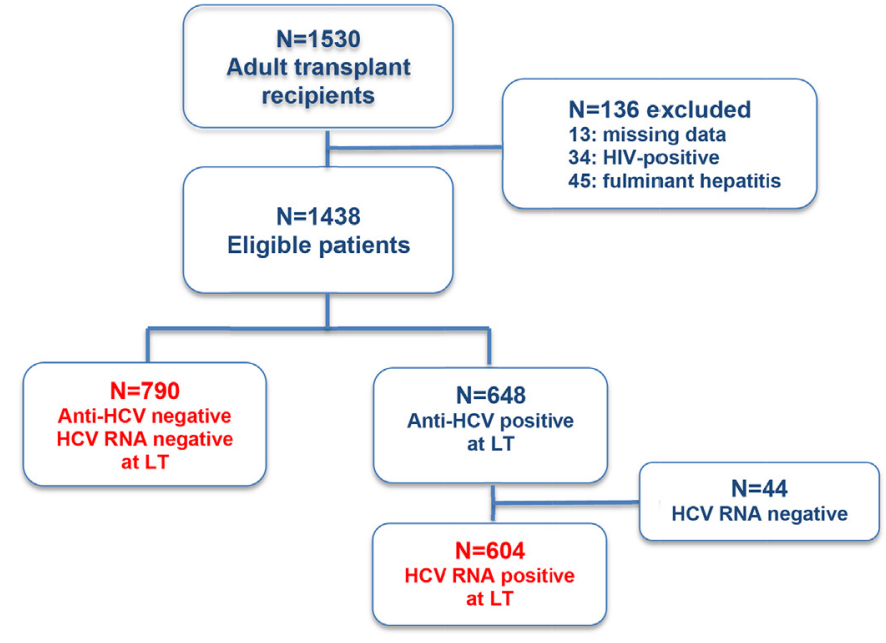

Fig. 1. Flow chart of patient disposition, including first consecutive adult liver transplant recipients from the Liver Match cohort. HCV, hepatitis C virus; LT, liver transplantation; HIV, human immunodeficiency virus.

achievement of a sustained virological response (SVR), HCV-related or unrelated graft loss. Causes of graft loss were recorded according to the European Liver Transplant Registry (ELTR) definitions.

All follow-up data were recorded prospectively, using detailed web-based forms every 3-6 months during the first year and yearly thereafter. The present analysis included follow-up data recorded until December 31, 2013, with a median follow-up after LT of 51 months for surviving grafts.

\subsection{Patient selection criteria}

Out of the 1530 LT cases, essential data regarding donor/recipient features and/or follow-up were missing in 13 cases only $(0.8 \%)$. Patients transplanted for fulminant hepatic failure (FHF, $n=45,2.9 \%$ ) and patients infected with human immunodeficiency virus (HIV, $n=34,2.3 \%$ ) were excluded from the analysis. The former were excluded since FHF patients are transplanted in a situation of urgency, which virtually precludes the possibility of donor/recipient matching. Moreover, FHF is known to entail per se a markedly increased risk of early graft failure. Conversely, HIV-positive recipients were excluded since their peri- and post-LT management is complex, requiring the use of anti-HIV drugs; in Italy, these patients may receive an organ only under a strict, still experimental, protocol.

Of the remaining 1438 adult recipients, 790 were anti-HCV negative and 648 anti-HCV positive at the time of LT. In the latter group, 44 patients without active HCV replication, based on undetectable serum HCV-RNA both at LT and in the post-transplant follow-up in the absence of antiviral therapy, were excluded from the analysis, since the primary aim of the study was to verify the impact of gender and donor/recipient gender mismatch on graft outcome in relation to HCV graft infection. Thus, for the purpose of this study, only the 604 anti-HCV positive patients that were also HCV-RNA positive in serum at LT were considered (Fig. 1).

\subsection{Outcome measures}

The main outcome measure was graft survival

The secondary outcome measure was graft loss associated with severe recurrent HCV disease, defined as graft loss from complications of advanced liver disease (i.e. variceal bleeding, hepatic encephalopathy, spontaneous bacterial peritonitis, sepsis) in the setting of documented advanced fibrosis or cirrhosis. 


\subsection{Statistical analysis}

Since a skew distribution, significantly departing from the normal density, was observed for several continuous variables, median, first and third quartile were preferred as summary statistics. Categorical variables were described by absolute and relative frequencies. Associations between categorical variables were evaluated by Chi-square test; Fisher exact test was preferred in case of sparse tables. Continuous covariates were compared by $t$-test or Wilcoxon rank-sum test when a significant departure from normality was detected.

The marginal effect of donor and recipient characteristics was evaluated by stratified Kaplan Maier survival curves as a preliminary step for the multivariable analysis. The log-rank test was used for comparison. Multivariable analysis was based on the Cox model [10] and all recorded variables were initially included. Note that DRI was computed assuming that local and regional US sharing were equivalent to regional and national sharing in Italy, respectively. Predictors of graft loss were identified by a non-automate backward selection, taking clinical interpretation and correlation structure among covariates into account. Plots of martingale residuals vs covariate values were used for detecting non-linear effects of continuous variables [11]. Possible time dependent effects were evaluated by plots and test statistics based on Schoenfeld residuals $[12,13]$. Once detected, both the time dependent and the non-linear effects were modelled extending the Cox model with the introduction of cubic spline functions in the linear predictor [14]. To evaluate the extent to which recipient gender may increase the risk of graft failure in presence of concomitant risk factors, patient survival at 4 years was estimated (with $95 \%$ confidence interval) for different designs of the selected covariates using the Cox model.

All statistical analyses were conducted using SAS and R software.

\section{Results}

\subsection{Survival in HCV-RNA positive vs HCV-all-negative recipients (both anti-HCV and HCV-RNA negative)}

After a median follow-up of 51 months, 194 graft losses occurred in $604 \mathrm{HCV}-\mathrm{RNA}$ positive recipients (32\%), and 181 among the $790 \mathrm{HCV}$-all-negative recipients (22.9\%). These events justify the lower graft survival observed in HCV-RNA positive recipients when compared to HCV-all-negative ones: 0.81 (s.e. 0.016) and 0.84 (s.e. 0.013 ) at year 1 after LT, 0.72 (s.e. 0.019) and 0.79 (s.e. 0.015) at year 3 , and 0.64 (s.e. 0.028 ) and 0.76 (s.e. 0.016 ) at year 5, respectively.

\subsection{Predictors of graft loss in HCV-RNA positive recipients at marginal (univariate) analysis}

Of the 194 graft losses observed among HCV-RNA positive recipients, 147 and 47 were observed in male (29.8\%) and female (42.3\%) recipients, respectively (Table 1 ). The higher rate of graft loss observed among female recipients was almost exclusively attributable to severe $\mathrm{HCV}$ recurrence (Table 2, panel b).

Among HCV-RNA positive LT recipients two characteristics of the recipient and three of the donor were more frequently found to be significantly associated with graft failure at marginal analysis. These included recipient female gender $(p=0.0107)$ and presence of complete portal vein thrombosis $(p=0.0325)$; increasing donor age $(p=0.0007)$, increasing DRI $(p=0.0018)$ and donor anti-HBc positivity $(p=0.0459)$ (Table 1$)$.

Recipient gender was significantly associated with a worse graft survival in HCV-RNA positive recipients, but not in HCV-allnegative ones (Fig. 2a and b). Notably, HCV-RNA positive female recipients differed significantly from HCV-RNA positive male
Graft survival
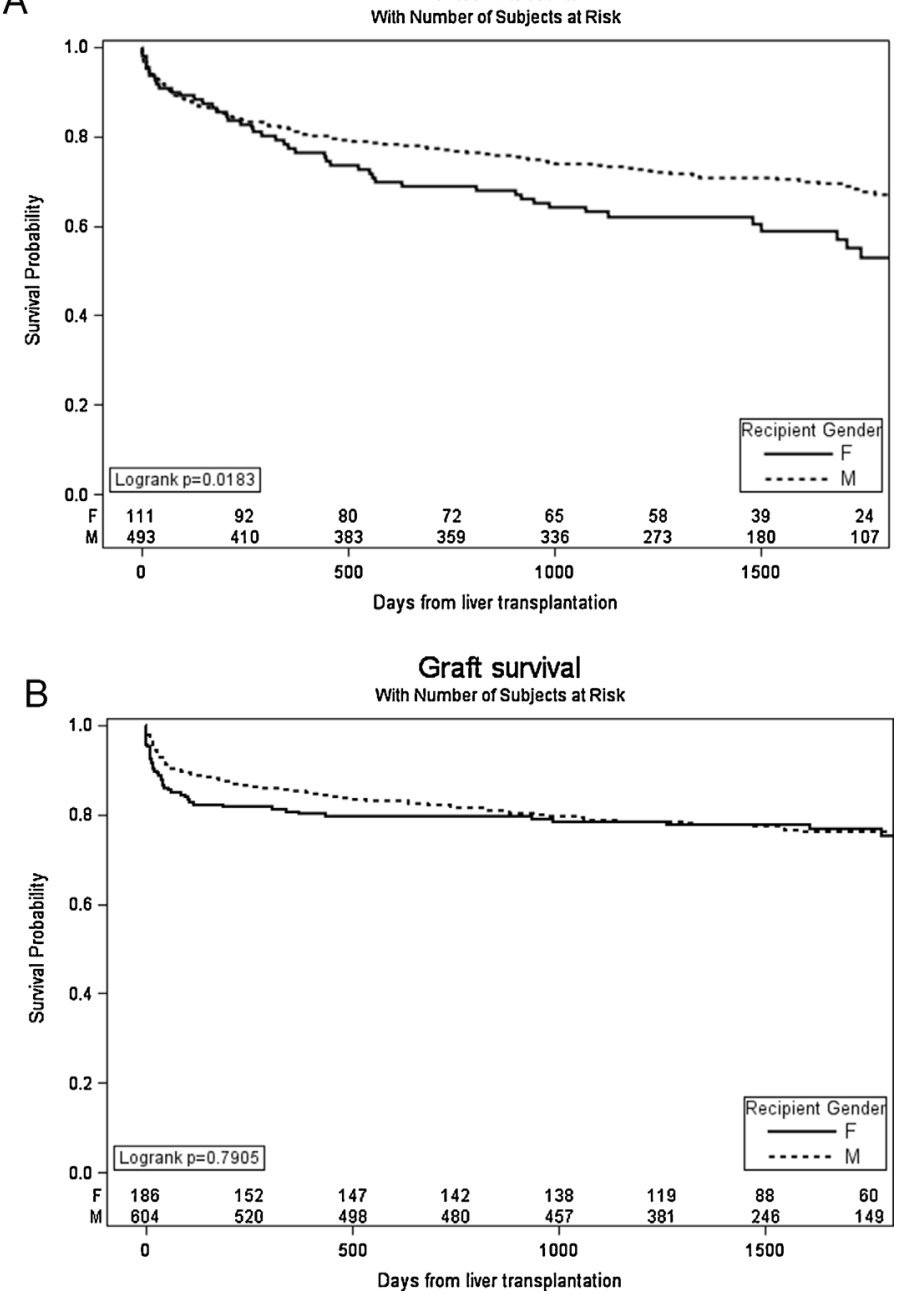

Fig. 2. Graft survival after liver transplantation in HCV-RNA positive and negative recipients stratified by gender. Panel A: HCV-RNA positive recipients; Panel B: HCVnegative recipients. $\mathrm{HCV}$, hepatitis $\mathrm{C}$ virus; M, Male; F, Female.

counterparts with respect to several relevant baseline characteristics: females were older, had less HCC, their donors had a higher age and a lower BMI, and their grafts were more frequently split livers (Table 2). All these variables were considered in the multivariate analysis.

When stratifying the outcome data for different donor and recipient gender matching combinations, at marginal analysis we found that female recipients receiving a graft from a male donor had a distinctly higher risk of graft loss compared to all other gender matching combinations (Fig. 3a). In contrast, all other gender matching combinations had a uniform and more favourable graft outcome. Conversely, no differences were observed among HCVall-negative recipients (Fig. $3 \mathrm{~b}$ ).

\subsection{Predictors of graft loss in HCV-RNA positive recipients at multivariable analysis}

All variables described in Supplementary Table S1 were initially included in the multivariable analysis, except for recipient insulin dependent diabetes, HCV genotype and donor history of diabetes, since their percent of missing data was above $5 \%$. Table 3 shows those emerging as significant independent predictors of graft loss at Cox regression in the population of HCV-RNA positive recipients. These included: female recipient gender, donor age, MELD at LT and complete portal vein thrombosis. 
Table 1

Baseline characteristics of 604 hepatitis C virus-RNA positive liver transplant recipients and their donors stratified by graft status.

\begin{tabular}{|c|c|c|c|c|c|}
\hline & \multicolumn{2}{|c|}{$\begin{array}{l}\text { Functioning graft } \\
n=410\end{array}$} & \multicolumn{2}{|l|}{$\begin{array}{l}\text { Graft loss } \\
n=194\end{array}$} & \multirow[t]{2}{*}{$p$-value } \\
\hline & Median or $n$ & Q1-Q3 or \% & Median or n & Q1-Q3 or \% & \\
\hline \multicolumn{6}{|l|}{ Recipient characteristics } \\
\hline Median age (years) & 56 & $49-62$ & 56 & $48-61$ & 0.2797 \\
\hline Gender ( $\mathrm{N}^{\circ}$ of males) & 346 & 84.39 & 147 & 75.77 & 0.0107 \\
\hline Median BMI & 25.3 & $23.2-27.7$ & 25.2 & $23.4-28.7$ & 0.7909 \\
\hline $\mathrm{HCC}$ & 240 & 58.54 & 98 & 50.52 & 0.0637 \\
\hline $\mathrm{N}^{\circ}$ of Milan out & 26 & 11.71 & 9 & 9.28 & 0.5664 \\
\hline Median MELD & 14 & $10-19$ & 15 & $11-21$ & 0.1222 \\
\hline Median sodium & 137 & $135-140$ & 137 & $133-140$ & 0.5284 \\
\hline Median INR & 1.4 & $1.2-1.7$ & 1.4 & $1.2-1.7$ & 0.2272 \\
\hline Median creatinine & 0.9 & $0.8-1.0$ & 1.0 & $0.8-1.1$ & 0.1146 \\
\hline Median bilirubin & 2.4 & $1.4-4.4$ & 2.7 & $1.3-5.9$ & 0.1786 \\
\hline $\mathrm{N}^{\circ}$ of previous abdominal surgery & 85 & 20.73 & 36 & 18.56 & 0.5329 \\
\hline $\mathrm{N}^{\circ}$ of complete portal vein thrombosis & 5 & 1.22 & 8 & 4.12 & 0.0325 \\
\hline $\mathrm{N}^{\circ}$ of insulin dependent diabetes & 65 & 16.62 & 41 & 23.03 & 0.0686 \\
\hline $\mathrm{N}^{\circ}$ of HCV genotype & & & & & 0.8523 \\
\hline 1 & 257 & 65.73 & 116 & 69.88 & \\
\hline 2 & 39 & 9.96 & 14 & 8.43 & \\
\hline 3 & 67 & 17.14 & 24 & 14.46 & \\
\hline 4 & 27 & 6.91 & 12 & 30.77 & \\
\hline 5 & 1 & 0.26 & - & - & \\
\hline \multicolumn{6}{|l|}{ Donor characteristics } \\
\hline Median age (years) & 55 & $41-66$ & 60.5 & $47-71$ & 0.0007 \\
\hline Gender ( $\mathrm{N}^{\circ}$ of males $)$ & 223 & 54.39 & 108 & 55.67 & 0.7679 \\
\hline Cause of death & & & & & 0.4842 \\
\hline $\mathrm{N}^{\circ}$ of trauma & 113 & 27.56 & 42 & 21.65 & \\
\hline $\mathrm{N}^{\circ}$ of cerebrovascular accident & 229 & 55.85 & 118 & 60.82 & \\
\hline $\mathrm{N}^{\circ}$ of post anoxyc & 23 & 5.61 & 11 & 5.67 & \\
\hline $\mathrm{N}^{\circ}$ of other causes & 45 & 10.98 & 23 & 11.86 & \\
\hline Median cold ischaemic time (h) & 7.3 & $6.0-8.8$ & 7.7 & $6.0-8.8$ & 0.5453 \\
\hline Median BMI & 24.8 & $22.7-27.3$ & 25.5 & $23.4-27.8$ & 0.0630 \\
\hline Median height $(\mathrm{cm})$ & 170 & $160-175$ & 170 & $160-175$ & 0.9405 \\
\hline $\mathrm{N}^{\circ}$ of history of diabetes & 33 & 8.55 & 17 & 9.88 & 0.6315 \\
\hline $\mathrm{N}^{\circ}$ of anti-HBc & 59 & 14.39 & 41 & 21.13 & 0.0459 \\
\hline Median DRI & 1.55 & $1.19-1.79$ & 1.66 & $1.36-1.85$ & 0.0018 \\
\hline Median sodium & 148 & $143-154$ & 148 & $142-155$ & 0.5896 \\
\hline $\mathrm{N}^{\circ}$ of split liver & 13 & 3.17 & 5 & 2.58 & 0.8019 \\
\hline
\end{tabular}

BMI, body mass index, HCC, hepatocellular carcinoma, MELD, model for end stage liver disease, anti-HBc, anti-hepatitis B core antigen antibody, DRI, donor risk index.

Multivariable analysis showed that the unfavourable impact of donor age on graft loss in HCV-RNA positive recipients starts increasing between 50 and 60 years, becoming remarkable after the age of 70 (Supplementary Fig. S1). Examples of how the graft survival may change in relation to different clinical settings and matching combinations are shown in Supplementary Table S2. Note that in all the proposed combinations female recipients have an approximate $10 \%$ lower expected graft survival than males at year 4.

\section{Discussion}

A negative effect of female gender on the outcome of LT in anti$\mathrm{HCV}$ positive recipients has been suggested based on retrospective data. Our study was conducted in a large, well-characterized population, ideally suited to test the validity of the putative predictors of poor graft outcome in HCV-infected LT recipients. The design of this study allows a better and unbiased understanding of the role of gender and other covariates on graft outcome. In fact: (a) the study analysed a large nation-wide cohort of consecutive adult patients transplanted over a limited period of 2 years, with prospective collection of all clinical events, and a median follow-up of 51 months; (b) the study recorded a wide number of covariates (with a negligible number of missing data), regarding donor, recipient and post-transplant course which were tested against the role of recipient gender and donor-recipient gender mismatch on graft outcome; (c) contrary to other studies, the analysis addressed only patients with active $\mathrm{HCV}$ infection, as a non-negligible number
(7.8\%) of patients with positive anti-HCV serology but undetectable HCV-RNA at LT were excluded from the analysis; (d) all cases of early graft loss were included in the analysis, avoiding possible biases due to inadvertent patient selection.

Our study unequivocally shows that women lose their graft more frequently than men secondary to more aggressive recurrent HCV infection, and confirms that the use of elderly donors is a strong predictor of poor graft outcome in HCV-infected LT recipients. On the other hand, our data do not confirm the claim that women may be at greater risk of graft loss when receiving a sex-mismatched graft (e.g., from a male donor), as multivariate analysis showed that this is not an independent risk factor.

The finding that in female recipients severe recurrence of HCV hepatitis is more frequent than men is in sharp contrast with known natural history of HCV infection in non-transplant patients, where males rather than females show faster disease progression and a worse outcome [2,3]. This discrepancy can be in part explained by the fact that immune-competent women may lose their advantage over men once they reach the post-menopausal state, possibly due to a favourable role played by oestrogens in controlling known cofactors for HCV disease progression such as inflammation $[15,16]$ and steatosis $[17,18]$. However, while the "male-like" faster fibrosis progression observed in post-LT females may be attributed to the hormonal changes associated with the menopausal state, the reason why women fare even worse than men after LT remains unclear.

In our prospective series "advanced donor age" is confirmed as a strong predictor of poor graft outcome in HCV-infected LT 
Table 2

Baseline characteristics of 604 hepatitis C virus-RNA positive liver transplant recipients and their donors stratified by gender.

\begin{tabular}{|c|c|c|c|c|c|}
\hline & \multicolumn{2}{|l|}{$\begin{array}{l}\text { Females } \\
n=111\end{array}$} & \multicolumn{2}{|l|}{$\begin{array}{l}\text { Males } \\
n=493\end{array}$} & \multirow[t]{2}{*}{$p$-value } \\
\hline & Median or $n$ & Q1-Q3 or \% & Median or $n$ & Q1-Q3 or \% & \\
\hline \multicolumn{6}{|l|}{ Recipient characteristics } \\
\hline Median age (years) & 59 & $53-63$ & 55 & $48-61$ & $<0.0001$ \\
\hline Median BMI & 25.3 & $22.7-29.0$ & 25.3 & $23.5-27.7$ & 0.9164 \\
\hline $\mathrm{HCC}$ & 50 & 45.05 & 288 & 58.42 & 0.0103 \\
\hline $\mathrm{N}^{\circ}$ of Milan out & 3 & 6.38 & 32 & 11.76 & 0.4462 \\
\hline Median MELD & 15 & $11-19$ & 15 & $10-19$ & 0.5260 \\
\hline Median sodium & 137 & $134-140$ & 137 & $134-140$ & 0.8403 \\
\hline Median INR & 1.5 & $1.3-1.8$ & 1.4 & $1.2-1.7$ & 0.0594 \\
\hline Median creatinine & 0.9 & $0.7-1.0$ & 0.9 & $0.8-1.1$ & 0.2935 \\
\hline Median bilirubin & 2.5 & $1.3-4.9$ & 2.5 & $1.4-4.7$ & 0.6541 \\
\hline $\mathrm{N}^{\circ}$ of previous abdominal surgery & 24 & 21.62 & 97 & 19.68 & 0.6435 \\
\hline $\mathrm{N}^{\circ}$ of complete portal vein thrombosis & 1 & 0.90 & 12 & 2.43 & 0.4798 \\
\hline $\mathrm{N}^{\circ}$ of insulin dependent diabetes & 19 & 18.27 & 87 & 18.71 & 0.9169 \\
\hline $\mathrm{N}^{\circ}$ of HCV genotype & & & & & 0.0707 \\
\hline 1 & 70 & 72.16 & 303 & 65.87 & \\
\hline 2 & 14 & 14.44 & 39 & 8.48 & \\
\hline 3 & 9 & 9.28 & 82 & 17.83 & \\
\hline 4 & 4 & 4.12 & 35 & 7.61 & \\
\hline 5 & 0 & - & 1 & 0.21 & \\
\hline \multicolumn{6}{|l|}{ Donor characteristics } \\
\hline Median age (years) & 61 & $45-71$ & 56 & $43-67$ & 0.1377 \\
\hline Gender ( $\mathrm{N}^{\circ}$ of males) & 33 & 29.73 & 298 & 60.45 & $<0.0001$ \\
\hline Cause of death & & & & & 0.1591 \\
\hline $\mathrm{N}^{\circ}$ of trauma & 23 & 20.72 & 132 & 26.77 & \\
\hline $\mathrm{N}^{\circ}$ of cerebrovascular accident & 72 & 64.86 & 275 & 55.78 & \\
\hline $\mathrm{N}^{\circ}$ of post anoxyc & 8 & 7.21 & 26 & 5.27 & \\
\hline $\mathrm{N}^{\circ}$ of other causes & 8 & 7.21 & 60 & 12.17 & \\
\hline Median cold ischaemic time (h) & 7.2 & $6.0-8.5$ & 7.5 & $6.0-8.8$ & 0.4333 \\
\hline Median BMI & 23.7 & $21.5-25.7$ & 25.4 & $23.4-27.8$ & $<0.0001$ \\
\hline Median height (cm) & 165 & $160-170$ & 170 & $163-175$ & $<0.0001$ \\
\hline $\mathrm{N}^{\circ}$ of history of diabetes & 6 & 5.77 & 44 & 9.69 & 0.2552 \\
\hline $\mathrm{N}^{\circ}$ of anti-HBc & 22 & 19.82 & 78 & 15.82 & 0.3059 \\
\hline Median DRI & 1.71 & $1.39-1.86$ & 1.55 & $1.21-1.79$ & 0.0003 \\
\hline Median sodium & 146 & $140-151$ & 148 & $143-155$ & 0.0586 \\
\hline $\mathrm{N}^{\circ}$ of split liver & 8 & 7.21 & 10 & 2.03 & 0.0088 \\
\hline Post-LT characteristics & $n$ & $\%$ & $N$ & $\%$ & $p$-value \\
\hline $\mathrm{N}^{\circ}$ of treated acute rejection & $7 / 111$ & 6.3 & $58 / 493$ & 11.7 & 0.1318 \\
\hline $\mathrm{N}^{\circ}$ of antiviral therapy $(\mathrm{y} / \mathrm{n})^{\mathrm{a}}$ & $46 / 59$ & 43.81 & $240 / 242$ & 49.79 & 0.2664 \\
\hline $\mathrm{N}^{\circ} \operatorname{SVR}(\mathrm{y} / \mathrm{n})^{\mathrm{b}}$ & $10 / 30$ & 25.00 & $65 / 153$ & 29.8 & 0.5375 \\
\hline $\mathrm{N}^{\circ}$ of HCV-related graft loss & $20 / 111$ & 18.1 & $39 / 493$ & 8.9 & 0.0022 \\
\hline
\end{tabular}

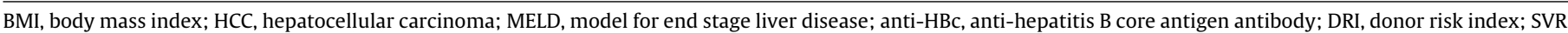
sustained virological response.

a 17 missing $(17 / 604=2.8 \%)$

b 28 missing $(28 / 604=4.6 \%)$.

recipients. The hazard ratio of donor age becomes evident when grafts are recovered from donors older than 60 years of age and the risk of graft loss dramatically increases when donors are older than 70. The field of HCV management in the LT setting will likely change dramatically in the near future, with the availability of new direct acting antivirals (DAAs). Their use prior and/or after surgery is likely to avoid HCV viral recurrence in most HCV-RNA positive recipients. Nevertheless, our findings suggest that women may need to be monitored more closely for disease progression and possibly treated earlier with DAAs. Furthermore, to what extent the use of new DAAs will be influenced by the gender of the recipient will have to be verified in the field. In conclusion, this study based on a large Italian population of LT recipients, demonstrates that females with recurrent HCV infection have a worse outcome and

Table 3

Hepatitis C virus-RNA positive liver transplant recipients and graft loss: results from the Cox model.

\begin{tabular}{|c|c|c|c|}
\hline \multirow[t]{2}{*}{ Variable (reference level or units) } & \multicolumn{3}{|c|}{$\begin{array}{l}\text { Hepatitis C virus-RNA positive recipients } \\
n=600 \text { ( } 4 \text { missing) } 194 \text { events }(32.3 \%)\end{array}$} \\
\hline & HR & $95 \% \mathrm{CI}$ & $p$-value \\
\hline Recipient gender (F vs M) & 1.44 & $(1.03,2.00)$ & 0.0319 \\
\hline MELD (10 units) & 1.25 & $(1.03,1.50)$ & 0.0220 \\
\hline Complete portal vein thrombosis (Yes vs No) & 2.40 & $(1.20,4.79)$ & 0.0134 \\
\hline Donor age (10 years) & 1.14 & $(1.05,1.24)$ & 0.0024 \\
\hline
\end{tabular}

MELD, model for end stage liver disease; F, female; M, male. 
A

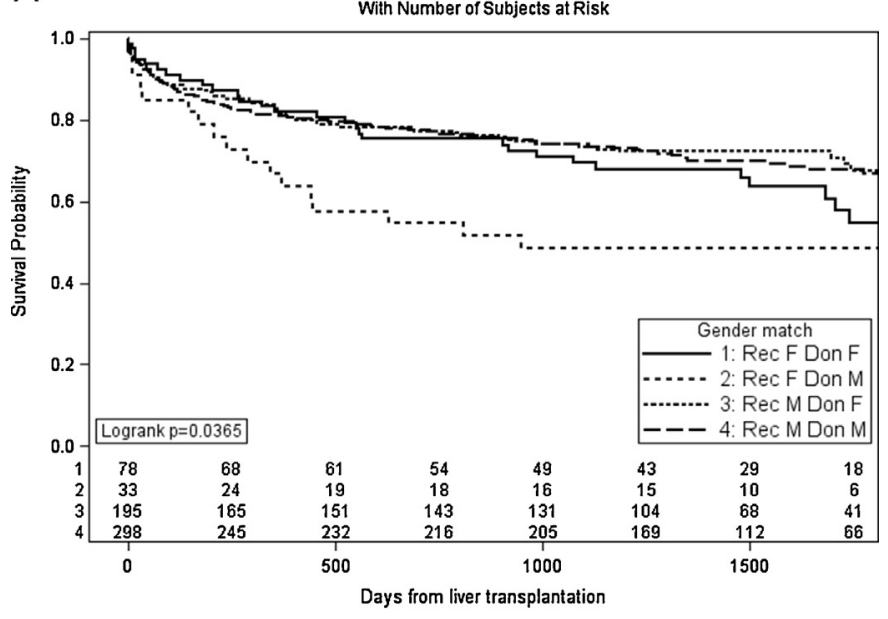

B

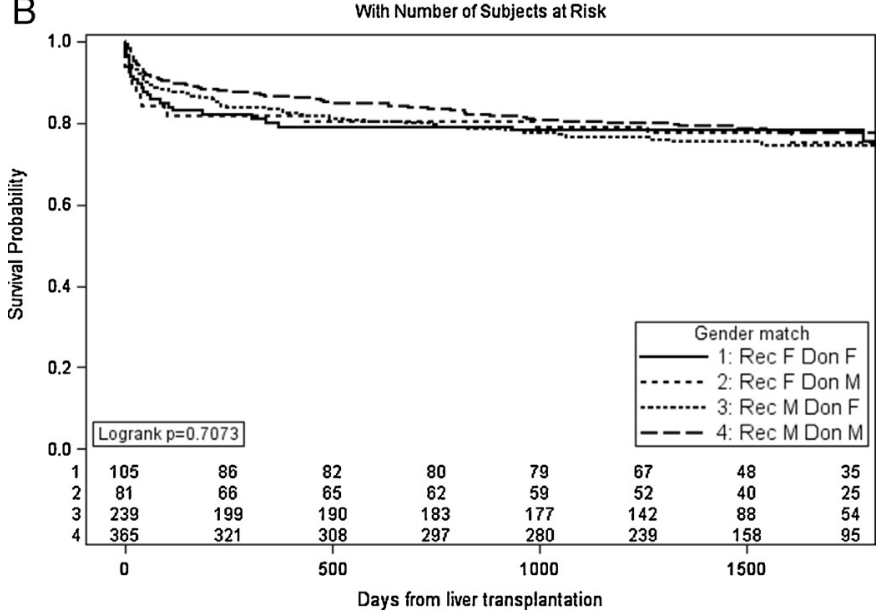

Fig. 3. Graft survival after liver transplantation in HCV-RNA positive and negative recipients stratified by donor/recipient gender matches. Panel A: HCV-RNA positive patients; Panel B: HCV-RNA negative recipients. HCV, hepatitis C virus; Rec, recipient; Don, donor; F, Female; M, Male.

the use of elderly donors is once again confirmed to be a strong predictor of poor graft outcome in HCV-infected LT recipients of both genders. The results of the prospective Liver Match cohort represent an ideal benchmark to evaluate what will be the impact of new DAAs on LT outcomes.

\section{Conflict of interest}

None declared.

\section{Funding}

This study was funded by the Italian Association for the Study of Liver (AISF) and the Italian National Transplant Center (CNT).

\section{Appendix A. Supplementary data}

Supplementary data associated with this article can be found, in the online version, at http://dx.doi.org/10.1016/j.dld.2015.04.006

\section{References}

[1] Avolio AW, Cillo U, Salizzoni M, et al. Balancing donor and recipient risk factors in liver transplantation: the value of D-MELD with particular reference to HCV recipients. American Journal of Transplantation 2011;11:2724-36.

[2] Poynard T, Bedossa P, Opolon P. Natural history of liver fibrosis progression in patients with chronic hepatitis C. The OBSVIRC, METAVIR, CLINIVIR, and DOSVIRC groups. Lancet 1997;349:825-32.

[3] Thomas DL, Astemborski J, Rai RM, et al. The natural history of hepatitis C virus infection: host, viral and environmental factors. Journal of the American Medical Association 2000;284:450-6.

[4] Belli LS, Burroughs AK, Burra P, et al. Liver transplantation for HCV cirrhosis: improved survival in recent years and increased severity of recurrent disease in female recipients: results of a long term retrospective study. Liver Transplantation 2007; 13:733-40.

[5] Lai JC, Verna EC, Brown Jr RS, et al. Hepatitis C virus infected women have a higher risk of advanced fibrosis and graft loss after liver transplantation than men. Hepatology 2011;54:418-25.

[6] Lai JC, Feng S, Roberts JP, et al. Gender differences in liver donor quality are predictive of graft loss. American Journal of Transplantation 2011:11:296-302.

[7] Angelico M, Cillo U, Fagiuoli S, et al. Liver match, a prospective observational cohort study on liver transplantation in Italy: study design and current practice of donor-recipient matching. Digestive and Liver Disease 2011;43:155-64.

[8] Everson GT, Terrault NA, Lok AS, et al. A randomized controlled trial of pre-transplant antiviral therapy to prevent recurrence of hepatitis $C$ after liver transplantation. Hepatology 2013;57:1752-62.

[9] Feng S, Goodrich NP, Bragg-Gresham JL, et al. Characteristics associated with liver graft failure: the concept of a donor risk index. American Journal of Transplantation 2006;6:783-90.

[10] Cox DR. Regression models and life tables. Journal of the Royal Statistical Society, Series B 1972;34:187-220.

[11] Therneau TM, Grambsch PM, Fleming TR. Martingale-based residuals for survival models. Biometrika 1990;77:147-60.

[12] Schoenfeld D. Partial residuals for the proportional hazards regression model. Biometrika 1982;69:239-41.

[13] Hess KR. Assessing time-by-covariate interactions in proportional hazards regression models using cubic spline functions. Statistics in Medicine 1994;13:1045-62.

[14] Heinzl H, Kaider A. Gaining more flexibility in Cox proportional hazards regression models with cubic spline functions. Computer Methods and Programs in Biomedicine 1997:54:201-8.

[15] Angelico M, Nardi A, Romagnoli R, et al. A Bayesian methodology to improve prediction of early graft loss after liver transplantation derived from the Liver Match Cohort. Digestive and Liver Disease 2014;46:340-7.

[16] Villa E, Karampatou A, Cammà C, et al. Early menopause is associated with lack of response to antiviral therapy in women with chronic hepatitis C. Gastroenterology 2011;140:818-29.

[17] Petta S, Cammà C, Di Marco V, et al. Insulin resistance and diabetes increase fibrosis in the liver of patients with genotype $1 \mathrm{HCV}$ infection. American Journal of Gastroenterology 2008;103:1136-44.

[18] Veldt BJ, Poterucha JJ, Watt KD, et al. Insulin resistance, serum adipokines and risk of fibrosis progression in patients transplanted for hepatitis C. American Journal of Transplantation 2009;9:1406-13. 